\title{
An Analysis of Mechanical Properties of the Developed Al/SiC-MMC's
}

\author{
K. L. Meena ${ }^{1}$, Dr. A. Manna ${ }^{2}$, Dr. S. S. Banwait ${ }^{3}$, Dr. Jaswanti ${ }^{4, *}$ \\ ${ }^{1}$ Department of Mechanical Engg, Chd. College of Engg \& Tech. Chandigarh, India \\ ${ }^{2}$ Department of Mechanical Engg, Punjab Engineering College Chandigarh, India \\ ${ }^{3}$ Department of Mechanical Engg, NITTTR, Chandigarh, India \\ ${ }^{4}$ Department of Electrical Engg, Chd. College of Engg \& Tech. Chandigarh, India \\ *Corresponding author: jaswanti98@yahoo.co.in
}

Received December 31, 2012; Revised January 30, 2013; Accepted February 28, 2013

\begin{abstract}
Metal Matrix Composites (MMC's) have evoked a keen interest in recent times for potential applications. Advance composite materials like $\mathrm{Al} / \mathrm{SiC}$ metal matrix composite is gradually becoming very important materials in manufacturing industries e.g. aerospace, automotive and automobile industries due to their superior properties such as light weight, low density, high strength to weight ratio, high hardness, high temperature and thermal shock resistance, superior wear and corrosive resistance, high specific modulus, high fatigue strength etc. In this study aluminum (Al-6063)/SiC Silicon carbide reinforced particles metal-matrix composites (MMCs) are fabricated by melt-stirring technique. The MMCs bars and circular plates are prepared with varying the reinforced particles by weight fraction ranging from 5\%,10\%,15\%, and 20\%. The average reinforced particles size of SiC are 220 mesh, 300 mesh, 400 mesh respectively. The stirring process was carried out at $200 \mathrm{rev} / \mathrm{min}$ rotating speed by graphite impeller for $15 \mathrm{~min}$. The microstructure and mechanical properties like Proportionality (MPa) limit, Tensile strength upper yield point (MPa), Tensile strength lower yield point (MPa), Ultimate tensile strength (MPa), Breaking strength(MPa), \% Elongation, \% Reduction in area, Hardness (HRB), Density (gm/cc), Impact Strength (N.m) are investigated on prepared specimens of MMCs. It was observed that the hardness of the composite is increased with increasing of reinforced particle weight fraction. The tensile strength and impact strength both are increased with rising of reinforced weight fraction. Different mechanical tests were conducted and presented by varying the particle size and weight fractions of $\mathrm{SiC}$.
\end{abstract}

Keywords: metal matrix composites (MMC's), silicon carbide (SiC), melt stirring technique

\section{Introduction}

Metal Matrix Composite (MMC) is engineered combination of metal (Matrix) and hard particles (Reinforcement) to tailored properties. Metal Matrix Composites (MMC's) have very light weight, high strength, and stiffness and exhibit greater resistance to corrosion, oxidation and wear. Fatigue resistance is an especially important property of Al-MMC, which is essential for automotive application. These properties are not achievable with lightweight monolithic titanium, magnesium, and aluminium alloys. Particulate metal matrix composites have nearly isotropic properties when compared to long fibre reinforced composite. But the mechanical behavior of the composite depends on the matrix material composition, size, and weight fraction of the reinforcement and method utilized to manufacture the composite. The distribution of the reinforcement particles in the matrix alloy is influenced by several factors such as rheological behavior of the matrix melt, the particle incorporation method, interaction of particles and the matrix before, during, and after mixing [1]. Non homogeneous particle distribution is one of the greatest problems in casting of metal matrix composites [2]. Nai and Gupta [3] reported that the average coefficient of thermal expansion of the high $\mathrm{SiCp}$ end was reduced as compared to that of the low SiCp end. Hashim et al. [4] reported that the distribution of the reinforcement material in the matrix must be uniform and the wettability or bonding between these substances should be optimized. Aluminum-silicon carbide metal matrix composite has low density and light weight, high temperature strength, hardness and stiffness, high fatigue strength and wear resistance etc. in comparison to the monolithic materials [5]. However, aluminum alloy with discontinuous ceramic reinforced $\mathrm{MMC}$ is rapidly replacing conventional materials in various automotive, aerospace, and automobile industries [6]. Amongst various processing routes stir casting is one of the promising liquid metallurgy technique utilized to fabricate the composites. The process is simple, flexible, and applicable for large quantity production. The liquid metallurgy technique is the most economical of all the available technique in producing of MMC [7]. Aluminum alloy-based composites containing 10wt\% alumina (size range: 150 $225 \mathrm{~mm}$ ) were prepared by liquid metallurgy technique using the vortex method [8,9]. The $\mathrm{ZnO}$ whiskers $25 \mathrm{vol} \%$ reinforced with Al-matrix composites were fabricated by a 
squeeze casting process [10]. The quartz-silicon dioxide particulates reinforced LM6 alloy matrix composites were fabricated by carbon dioxide sand molding process [11]. Various researchers have utilized conventional stir casting technique for producing MMC [12,13,14,15] but still applied research is needed for successful utilization of the process for manufacturing of MMC.

In this study stir casting is accepted as a particularly promising route, currently can be practiced commercially. Its advantages lie in its simplicity, flexibility and applicability to large quantity production. It is also attractive because, in principle, it allows a conventional metal processing route to be used, and hence minimizes the final cost of the product. This liquid metallurgy technique is the most economical of all the available routes for metal matrix composite production [16], and allows very large sized components to be fabricated. The cost of preparing composites material using a casting method is about one-third to half that of competitive methods, and for high volume production, it is projected that the cost will fall to one-tenth [17]. In general, the solidification synthesis of metal matrix composites involves producing a melt of the selected matrix material followed by the introduction of a reinforcement material into the melt. To obtain a suitable dispersion the stir casting method is used. The solidification of the melt containing suspended $\mathrm{SiC}$ particles is done under selected conditions to obtain the desired distribution.

From the past review, it is found that the number of research work on wear behaviour of MMCs have been published, but only few work related to the influence of weight fraction on mechanical properties like tensile strength, hardness, impact strength, percentage of elongation etc. have been reported. In this study, different weight fractions of Silicon Carbide particulates are added with aluminium matrix to fabricate the $\mathrm{Al} / \mathrm{SiC}$ metal matrix composites. Different samples have been fabricated by melt-stirring casting and their microstructure, hardness, tensile strength, and impact strength are studied. In this study the influences of the reinforced particulate size (220 mesh, 300 mesh, 400 mesh) and weight fraction (5\%, $10 \%, 15 \%$, 20\%) on mechanical properties like Proportionality (MPa) limit, Tensile strength upper yield point $(\mathrm{MPa})$, Tensile strength lower yield point $(\mathrm{MPa})$, Ultimate tensile strength (MPa), Breaking strength (MPa), \% Elongation, \% Reduction in area, Hardness (HRB), Density (gm/cc), Impact Strength (N.m) are investigated.

\section{Fabrication of $\mathrm{Al} / \mathrm{SiC}$ Metal Matrix Composites}

Silicon Carbide $(\mathrm{SiC})$ reinforced particles of average particle size 220 mesh, 300 mesh, 400 mesh respectively are used for casting of $\mathrm{Al} / \mathrm{SiC}-\mathrm{MMCs}$ by melt-stir technique. Table 1 represents the chemical composition of commercially available Al-matrix used for manufacturing of MMC. Different dimensions of round bars with $5 \mathrm{vol} \%$, $10 \mathrm{vol} \%, 15 \mathrm{vol} \%$ and $20 \%$ of reinforced particles of size 220 mesh, 300 mesh, 400 mesh respectively.

Experiments were carried out to study the effect of settling the reinforced particulates on the solidification microstructure and mechanical properties of the cast
MMC. In the present study, commercially available aluminium (AA6063) is used as matrix reinforced with Silicon Carbide (SiC) particulates. The melting was carried out in a clay-graphite crucible placed inside the resistance furnace. An induction resistance furnace with temperature regulator cum indicator is utilized for melting of $\mathrm{Al} / \mathrm{SiC}-\mathrm{MMCs}$. Figure 1 (a) and (b) show an induction resistance furnace and temperature regulator cum indicator, respectively. A design and developed stirring setup is shown in Figure 1 (c). Aluminium alloy (Al 6063) was first preheated at $450^{\circ} \mathrm{C}$ for 2 hours before melting and $\mathrm{SiC}$ particulates were preheated at $1100^{\circ} \mathrm{C}$ for 1 hour 30 minutes. to improve the wetness properties by removing the absorbed hydroxide and other gases. The furnace temperature was first raised above the melting temperature, that is, $750^{\circ} \mathrm{C}$, to melt the matrix completely and then it was cooled down to just below the melting temperature to keep the slurry in a semi-solid state. At this stage the preheated $\mathrm{SiC}$ particles were added and mixed mechanically. The composite slurry was then reheated to a fully liquid state and mechanical mixing was carried out for $20 \mathrm{~min}$ at $200 \mathrm{rpm}$ average stirring speed. In the final stage of mixing, the furnace temperature was controlled within $760 \pm 10^{\circ} \mathrm{C}$ and the temperature was controlled at $740^{\circ} \mathrm{C}$. Moulds (size $40 \mathrm{~mm}$ diameter $\times 170 \mathrm{~mm}$ long) made of IS-1079/3.15mm thick steel sheet were preheated to $350^{\circ} \mathrm{C}$ for 2 hours before pouring the molten $\mathrm{Al} / \mathrm{SiC}$ MMC. Figure 2 (a) shows the prepared permanent mould made of steel sheet utilized for casting of $40 \mathrm{~mm}$ diameter $\times 170 \mathrm{~mm}$ long bar. Figure 2 (b) shows mixing again manually before pouring. Figure 2 (c) shows pouring mixture of molten $\mathrm{Al}$ and $\mathrm{SiC}$ particles. Then fabrication of composite was followed by gravity casting. Similar process was adapted for preparing the specimens of varying mesh size and weight fractions.

Table 1. Chemical composition of matrix $\mathrm{Al} 6063$ alloy

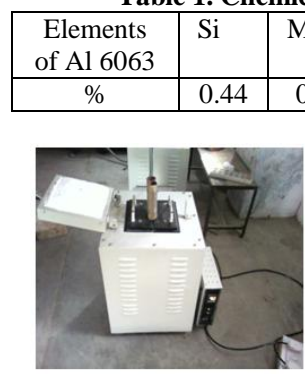

(a)

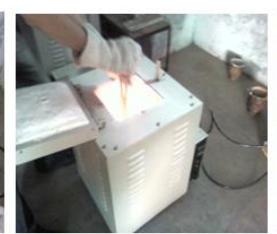

(b)

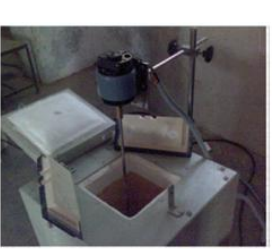

(c)
Figure 1. (a), (b) Induction resistance furnaces with temperature regulator cum indicator and (c) Melt-stirring setup utilized for casting of composites

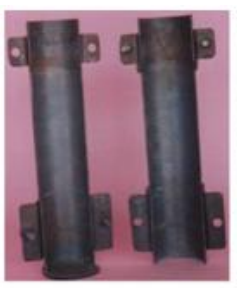

(a)

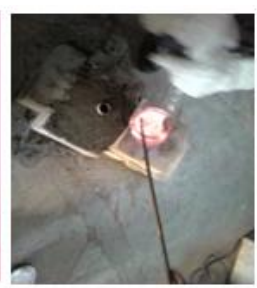

(b)

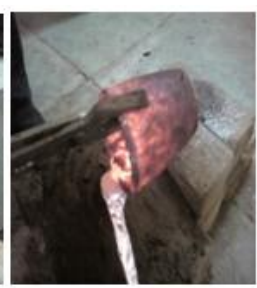

(c)
Figure 2. (a) Permanent mould for $40 \mathrm{~mm}$ diameter round bar (b) Mixing again manually before Pouring (c) Pouring mixture of molten $\mathrm{Al}$ and $\mathrm{SiC}$ particles 


\section{Results and Discussion}

Various Experiments were conducted on fabricated MMCs samples by varying weight fraction of $\mathrm{SiC}(5 \%$, $10 \%, 15 \%, 20 \%$, ) and size of SiC particles (220 mesh, 300 mesh, 400 mesh) to analyze the casting performance characteristics of $\mathrm{Al} / \mathrm{SiC}-\mathrm{MMCs}$.

\subsection{Microstructure}

Metallographic samples were sectioned from the cylindrical cast bars. A $0.5 \%$ HF solution was used to etch the samples wherever required. To see the difference in distribution of $\mathrm{SiC}$ particles in the aluminium matrix, microstructure of samples were developed on Inverted type Metallurgical Microscope (Make: Nikon, Range-X50 to X1500). Figure 3 shows Micrograph of Al/Sic-MMC's samples for different Sizes (220 mesh, 300 mesh, 400 mesh) and weight fraction $(5 \%, 10 \%, 15 \%, 20 \%$,) of SiC particles. Optical micrographs showed reasonably uniform distribution of $\mathrm{SiC}$ particles. In this $\mathrm{Al}$ matrix $\mathrm{SiC}$ particles are clearly labeled.

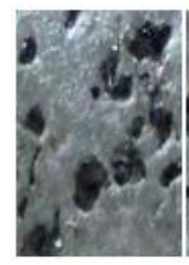

(a)

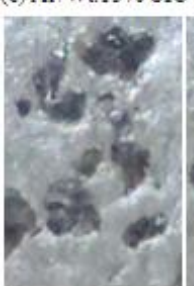

(a)

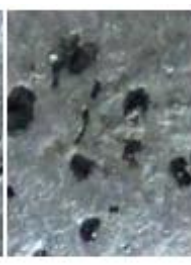

(b)

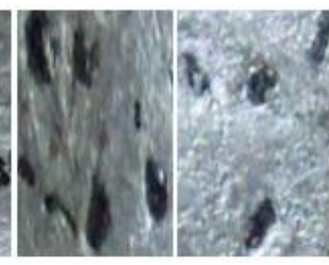

(c)

(d)

\section{C, 220 mesh}

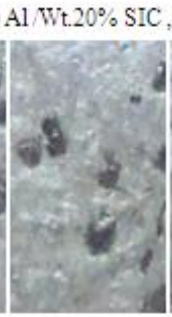

(c)

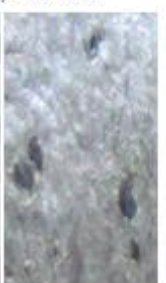

(d) $\begin{array}{ll}\text { (a) } \mathrm{Al} / \mathrm{Wt} .5 \% \mathrm{SIC}, 300 \text { mesh } & \text { (b) } \mathrm{Al} \mathrm{Wt} .10 \% \mathrm{SIC}, 300 \text { mesh }\end{array}$ (c) $\mathrm{Al}$ Wt. $15 \%$ SIC , 300 mesh (d) Al Wt.20\% SIC, 300 mesh

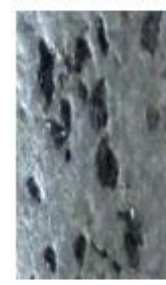

(a)

(a) Al $15 \mathrm{t} 5 \%$ SIC, 400 mesh

(c) Al Wt $15 \%$ SIC, 400 mesh

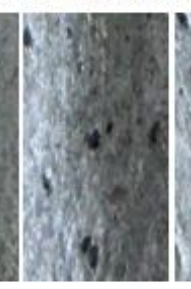

(c)

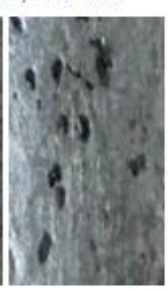

(d)

(b) Al $1 \mathrm{Wt} 10 \%$ STC, $400 \mathrm{mesh}$ (d) Al $\mathrm{Wt} 20 \%$ SIC, 400 mesh
Figure 3. Micrograph of Al/Sic-MMC's samples for different Sizes and weight fraction of $\mathrm{SiC}$ particles

\subsection{Tensile Strength}

The tensile test was carried out at room temperature on Universal Testing Machine Model-UTN-20, Sr.No.4/79/239, Max. Capacity-2000 kgs, Make Blue Star Ltd. Figure 4 shows standard dimensions of specimen for Tensile Test. Test specimens of standard dimensions as shown in Figure 5. were prepared of Al/Sic-MMC's for different size (220 mesh, 300 mesh, 400 mesh) and weight fraction $(5 \%, 10 \%, 15 \%, 20 \%)$ of $\mathrm{SiC}$ particles.

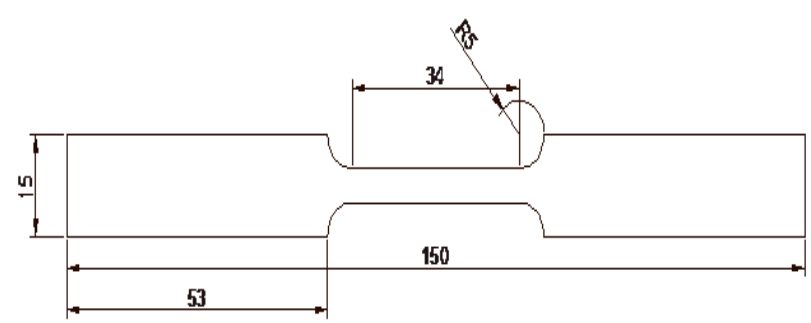

Figure 4. Standard specimen for Tensile Test
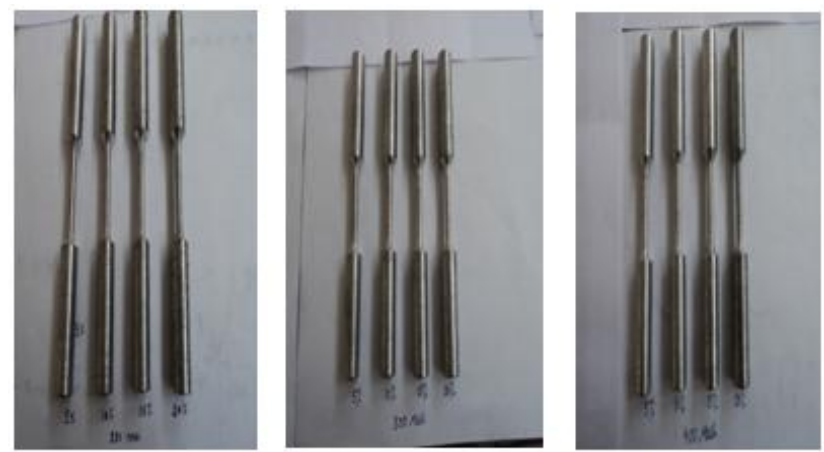

Figure 5. Standard specimen prepared by varying the mesh size and Wt. fraction of SiC for Tensile Test

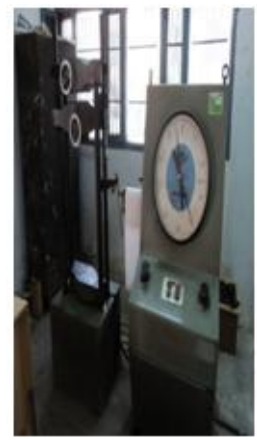

(a)

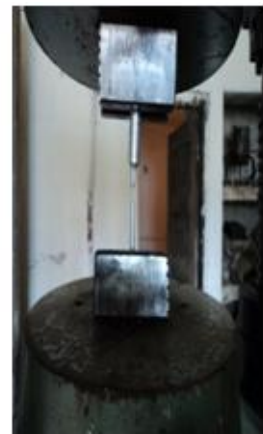

(b)

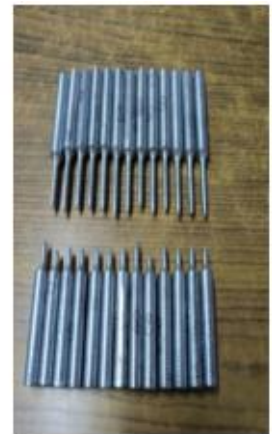

(c)
Figure 6. (a) UTM Machine (b) Testing of specimen on UTM Machine (c) Specimens after test

Procedure of Tensile Test is shown by Figure 6. (a) and (b) In Figure 6 (c) Twelve Specimens are shown after test. Graphs were plotted between tensile force (kgf) and Extension (mm) for twelve specimens. The values of tensile force are plotted on vertical axes and extension on horizontal axes. The specimen passes through the clearly defined stages i.e. limit of proportionality, Upper yield value, lower yield value, ultimate stress value and finally fractures strength value.

\subsection{Hardness}

The Rockwell hardness test was done on Rockwell hardness tester as shown in Figure 8 (a) Model RAB, Sr.No.SN 4144, make SEU Pvt. Ltd. Twelve samples of Al/Sic-MMC's for different sizes and weight fraction of $\mathrm{SiC}$ particles were prepared. Figure 8. (b) and (c) Shows samples after test and hardness value on dial. The Rockwell hardness values with reference to scale HRB were taken for all samples and shown by graphs. 

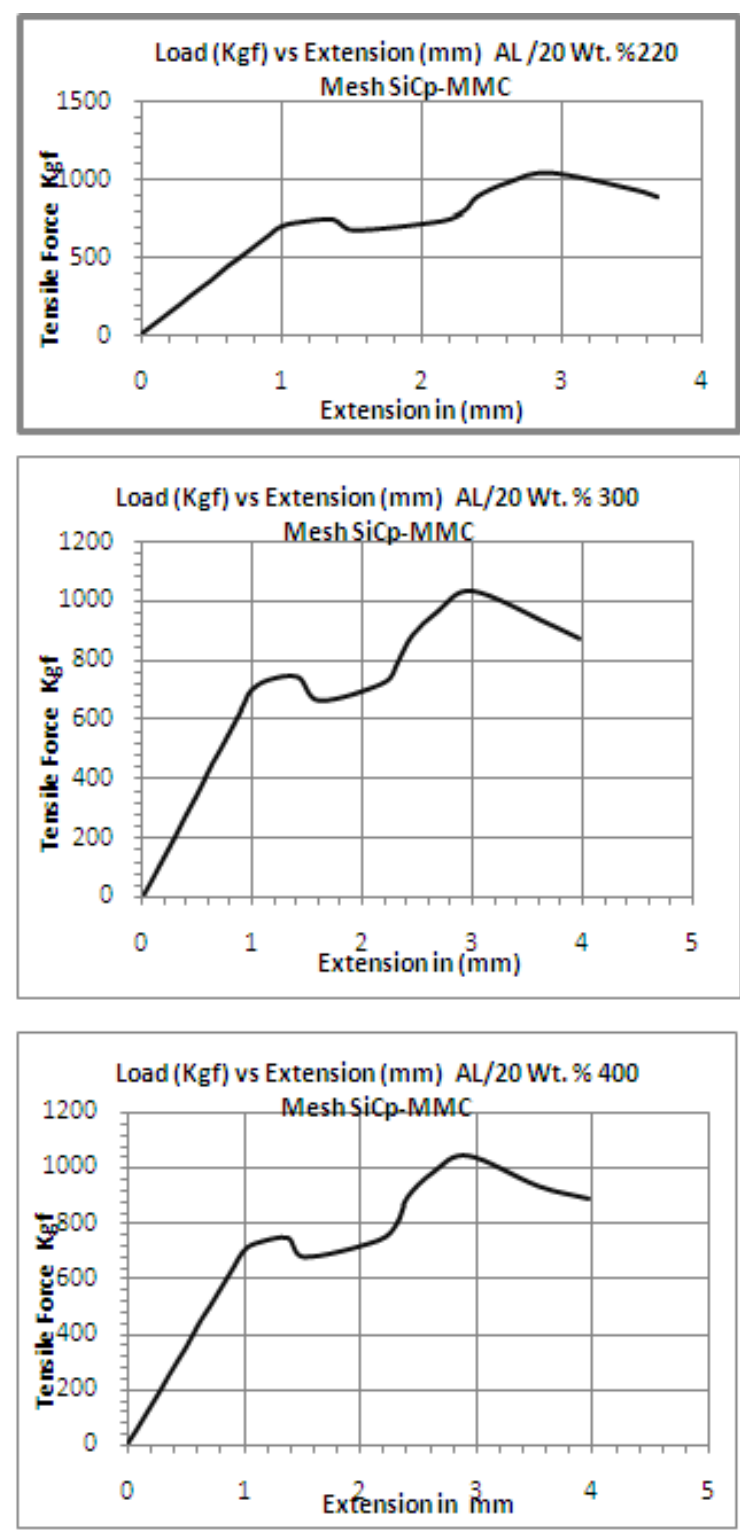

Figure 7. Graphs were plotted between Tensile force (kgf) and Extension (mm) for twelve specimens

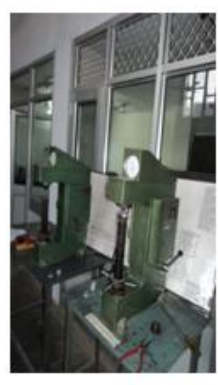

(a)

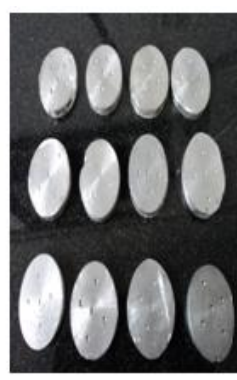

(b)

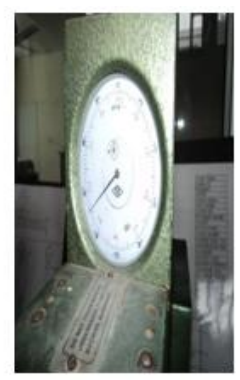

(c)
Figure 8. From left (a) hardness Tester (b) samples after test (c) hardness value on dial

\subsection{Density}

Density of Twelve samples of Al/Sic-MMC's for different Sizes and weight fraction of $\mathrm{SiC}$ particles were measured by using Archimedean principle. Standard blocks of $15 \times 15 \times 10 \mathrm{~mm}$ were made as sample pieces. The schematic of the set up designed and fabricated for the density measurement. Steel rod of $2 \mathrm{~mm}$ diameter is bent in $U$ shape, one end of the rod is brazed with the rectangular steel sheet of $3 \mathrm{~mm}$ thickness and the other end is free. The whole set up is placed over the electronic weighing machine pan having least count (LC) of $0.1 \mathrm{mg}$. Distilled water was filled up to a mark in a standard beaker of $100 \mathrm{ml}$, which was placed over the wooden slab and it should be free from the electronic balance. Sample pieces were freely suspended with a piece of thread from the upper end of the steel rod. Initially weight of the sample in air $\left(\mathrm{w}_{1}\right)$ is measured, later the same sample was immersed in distilled water, and weight $\left(\mathrm{w}_{2}\right)$ of the sample was recorded. The actual density was calculated using the following equation. Density $=\mathrm{w}_{1} /\left(\mathrm{w}_{1}-\mathrm{w}_{2}\right)$. Results are shown by graphs.

\subsection{Impact Strength}

Impact Test was carried out on Izod Impact Testing Machine and results were recorded in table. According to size and weight fraction of $\mathrm{SiC}$ particles Twelve Specimens Al/Sic-MMC's were prepared of Square crosssection of size (10X10X75) with single V-notches as shown in Figure 9 (a), (b) and (c). The size of V-notches is $45^{\circ}$ and $2 \mathrm{~mm}$ depth. Figure 9 (d) shows specimens of Al/Sic-MMC's after IZOD Test.

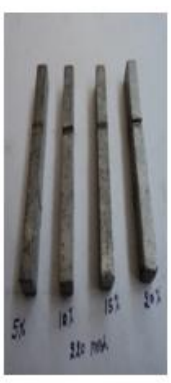

(a)

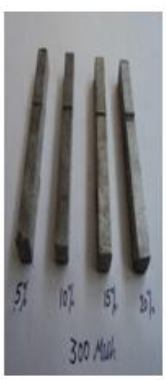

(b)

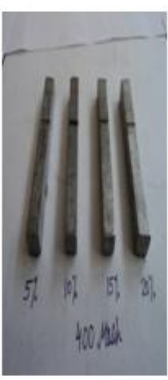

(c)

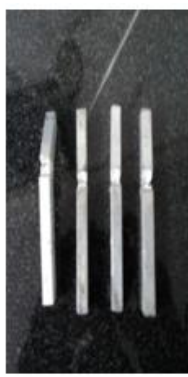

(d)
Figure 9. (a), (b) and (c) Twelve Specimens of Al/Sic-MMC's (d) Specimens of Al/Sic-MMC's after IZOD Test

\subsection{Result Graph}

Effect of size and weight fraction of $\mathrm{SiC}$ particles of Al/Sic-MMC's on mechanical properties like Proportionality $(\mathrm{MPa})$ limit, Tensile strength upper yield point $(\mathrm{MPa})$, Tensile strength lower yield point (MPa), Ultimate tensile strength $(\mathrm{MPa})$, Breaking strength (MPa), \% Elongation, \% Reduction in area, Hardness (HRB), Density (gm/cc), Impact Strength (N.m) are presented in graphs [Figure 10 to 19] as shown hereunder. In these graphs all above properties are taken on vertical axes and $\mathrm{Wt} . \%$ of $\mathrm{SiC}$ on horizontal axes.

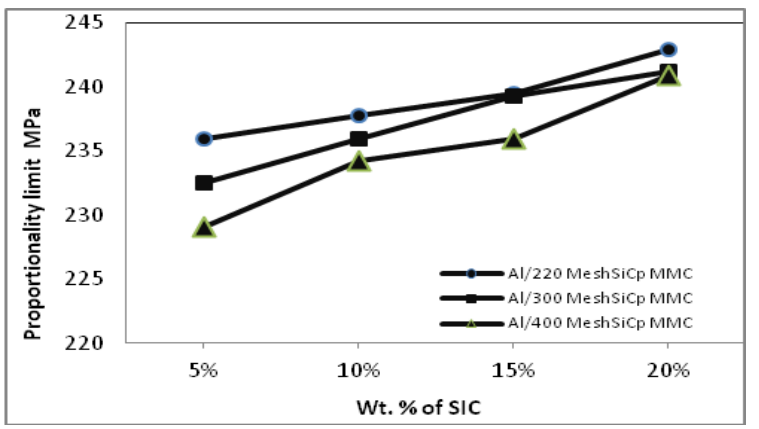

Figure 10. Proportionality (MPa) limit Vs Wt.\% of SiC 


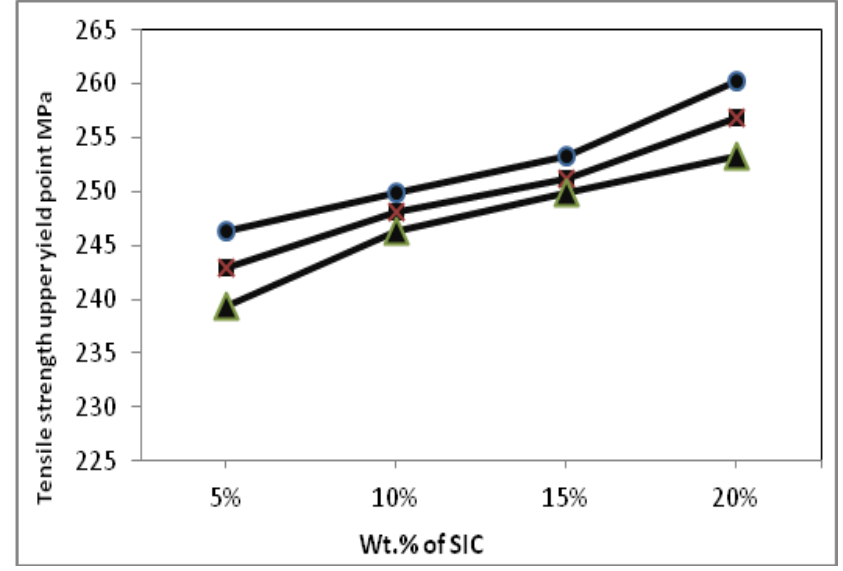

Figure 11. Tensile strength upper yield point (MPa) Vs Wt.\% of SiC

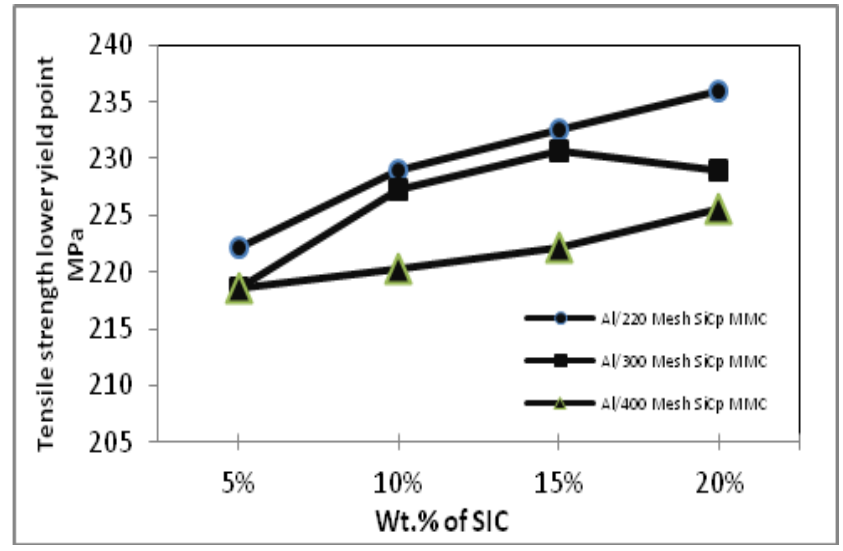

Figure 12. Tensile strength lower yield point (MPa)Vs Wt.\% of SiC

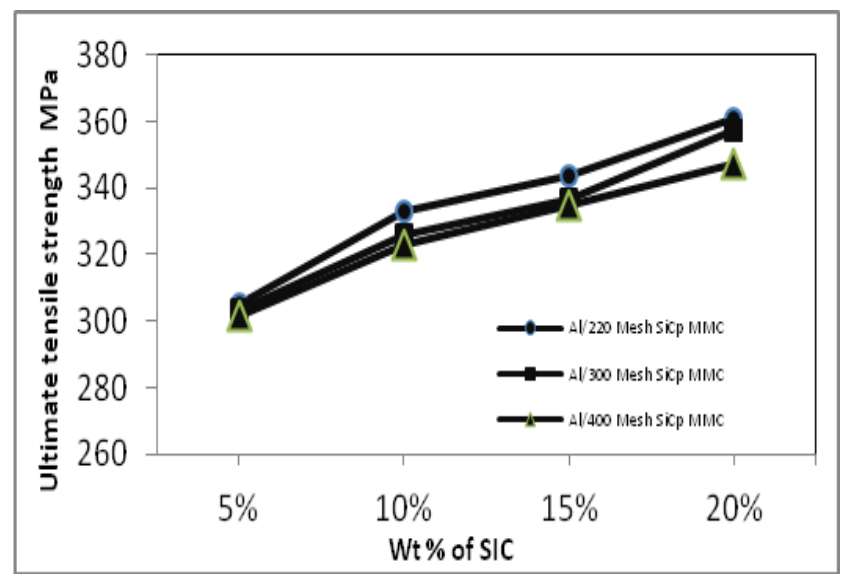

Figure 13. Ultimate tensile strength (MPa)Vs Wt.\% of SiC

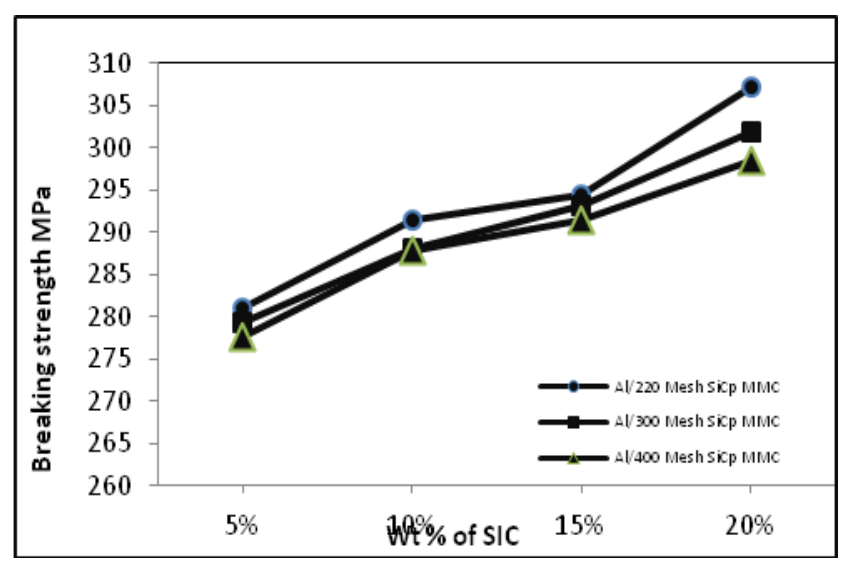

Figure 14. Breaking strength(MPa)Vs Wt.\% of SiC

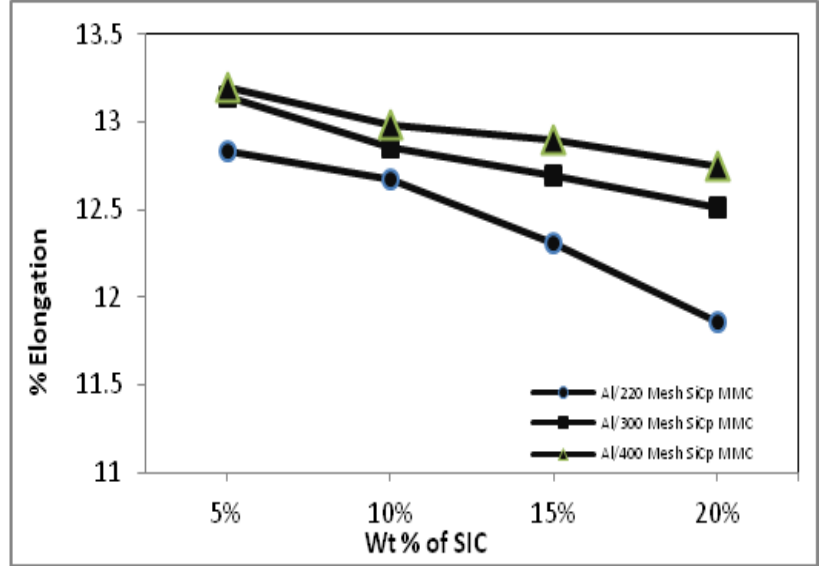

Figure 15. \% Elongation Vs Wt.\% of SiC

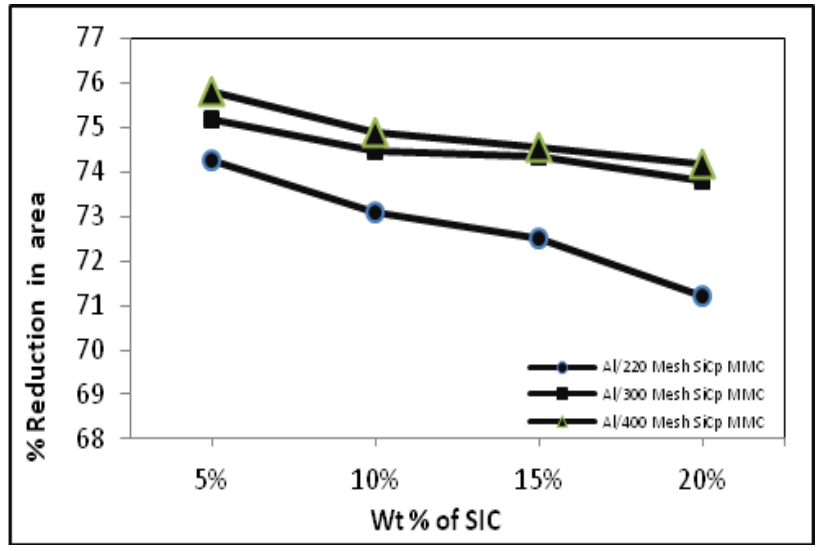

Figure 16. \% Reduction in area Vs Wt.\% of SiC

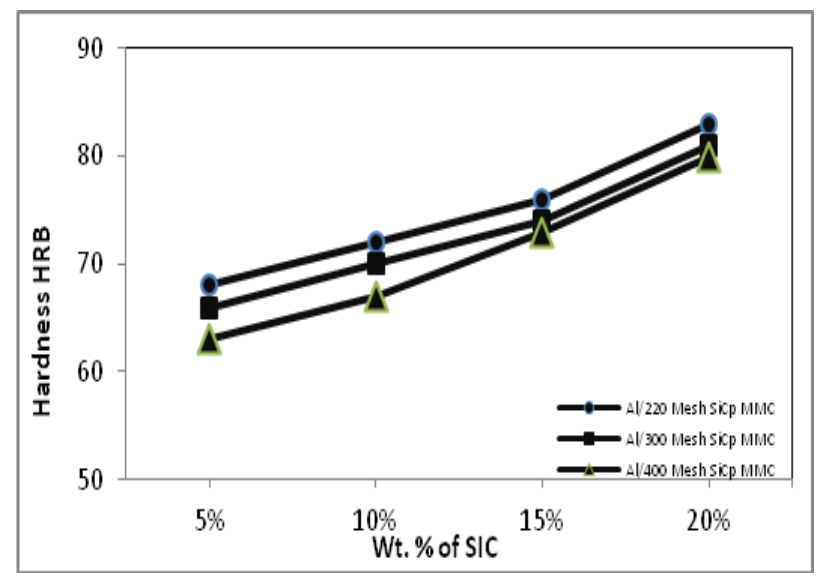

Figure 17. Hardness (HRB) Vs Wt.\% of SiC

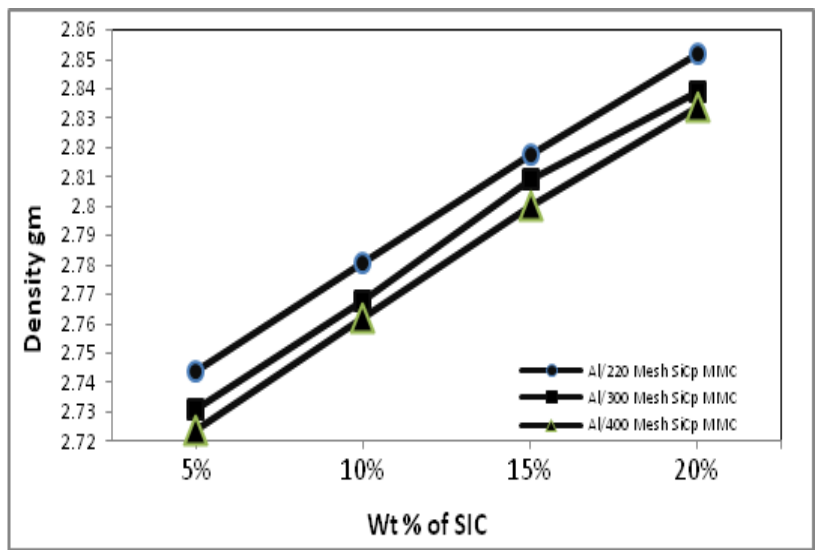

Figure 18. Density (gm/cc)Vs Wt.\% of SiC 


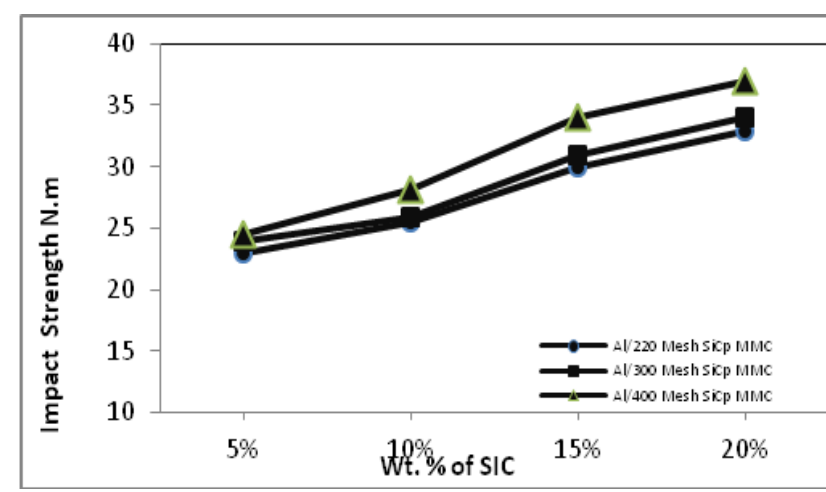

Figure 19. Impact Strength (N.m)Vs Wt.\% of SiC

\section{Conclusions}

The experimental study reveals following conclusions:

(a) Microstructure: Optical micrographs showed reasonably uniform distribution of $\mathrm{SiC}$ particles and this is good agreement with earlier work. Homogenous dispersion of $\mathrm{SiC}$ particles in the $\mathrm{Al}$ matrix shows an increasing trend in the samples prepared by applying stirring casting technique.

(b)Tensile Strength: From the result graphs Proportionality (MPa) limit, Tensile strength upper yield point $(\mathrm{MPa})$, Tensile strength lower yield point $(\mathrm{MPa})$, Ultimate tensile strength $(\mathrm{MPa})$ and Breaking strength $(\mathrm{MPa})$ increases with the increase in reinforced particulate size(220 mesh, 300 mesh, 400 mesh) and weight fraction $(5 \%, 10 \%, 15 \%, 20 \%)$ of $\mathrm{SiC}$ particles. \% Elongation and $\%$ Reduction in area decreases with the increase in reinforced particulate size (220 mesh, 300 meshes, 400 mesh) and weight fraction $(5 \%, 10 \%, 15 \%, 20 \%)$ of $\mathrm{SiC}$ particles.

(c) Hardness (HRB) and Density (gm/cc) increases with the increase in reinforced particulate size 220 mesh, 300 mesh, 400 mesh) and weight fraction (5\%,10\%,15\%, $20 \%$ ) of SiC particles. Maximum Hardness $(\mathrm{HRB})=83$ and Maximum Density $(\mathrm{gm} / \mathrm{cc})=2.852 \mathrm{gm} / \mathrm{cc}$ has been obtained at $20 \%$ weight fraction of 220 mesh size of $\mathrm{SiC}$ particles.

(d) Impact Strength (N.m) decreases with the increase in reinforced particulate size(220 mesh, 300 mesh, 400 mesh) and increases with the increase in weight fraction ( $5 \%, 10 \%, 15 \%, 20 \%$ ) of $\mathrm{SiC}$ particles. Maximum Impact Strength $=37.01 \mathrm{~N}-\mathrm{m}$ has been obtained at $20 \%$ weight fraction of 400 mesh size of $\mathrm{SiC}$ particles.

\section{References}

[1] Hashim, J., Looney, L. and Hashmi, M.S.J., "Particle Distribution in Metal Matrix Composites," Part-I, Journal of Materials Processing Technology, 123: 251-257. 2002.

[2] Nather, S., Brabazon, D. and Looney, L., "Simulation of the Stir Casting Process," Journal of Materials Processing Technology, 143-144: 567-571. 2003.

[3] Nai, S.M.L. and Gupta, M. ,'Synthesis and Characterization of Free Standing, Bulk Al/Sicp Functionally Gradient Materials: Effects of Different Stirrer Geometries," Material Research Bulletin, 38: 1573-1589. 2003.

[4] Hashim, J., Looney, L. and Hashmi, M.S.J., "Metal Matrix Composites: Production by the Stir Casting Method," Journal of Materials Processing Technology, 92-93: 1-7. 1999.

[5] Manna, A. and Bhattacharyya, B., "Study on Different Tooling Systems during Turning for Effective Machining of $\mathrm{Al} / \mathrm{SiC}$ MMC," The Institution of Engineers (India) Journal-Production, 83: 46-50. 2003

[6] Allison, J.E. and Cole, G.S., "Metal Matrix Composite in Automotive Industry: Opportunities and Challenges," Journal of Mechanical Science, 19-24. 1993.

[7] Surappa, M.K., "Microstructure Evolution during Solidification of DRMMCs: State of the Art," Journal of Materials Processing Technology, 63: 325-333. 3078 A. MANNA ET AL.1997.

[8] Yang, J., Pickard, S.M., Ctedy, C., Evans, A.G. and Mehrabian, T.,'The Stress/Strain Behavior of Aluminium Matrix Composites with Discontinuous Reinforcements," Acta Metallurgica Materialia, 39: 1863-1870. 1997.

[9] Lloyd, D.J., Lagace, H., Mcleod, A. and Morris, P.L. (1989). Micro Structural Aspect of Aluminium Silicon Carbide Particulate Composites Produced by a Casting Method, Materials Science and Engineering, A107: 73-79.

[10] Guo, Z., Xiong, J., Yang, M. and Li, W., "Microstructure and Properties of Tetrapod-like $\mathrm{ZnO}$ Whiskers Reinforced Al Matrix Composite," Journal of Alloy and Compounds, 461: 342-345. 2008.

[11] Sulaiman, S., Sayuti, M. and Samin, R., "Mechanical Properties of the As-Cast Quartz Particulate Reinforced LM6 Alloy Matrix Composites," Journal of Material Processing Technology, 201: 731-735. 2008.

[12] Zhou, W. and Xu, Z.M., "Casting of SiC Reinforced Metal Matrix Composites," Journal of Materials Processing Technology, 63: 358-363. 1997.

[13] Gupta, M., Lai, M.O. and Lim, C.Y.H., "Development of a Novel Hybrid Aluminium Based Composite with Enhanced Properties," Journal of Materials Processing Technology, 176: 191-199. 2006.

[14] Ourdjini, A., Chew, K.C. and Khoo, B.T., "Settling of Silicon Carbide Particles in Cast Metal Matrix Composites," Journal of Materials Processing Technology, 116: 72-76. 2001.

[15] Srivatsan, T.S., Sudarshan, T.S. and Lavernia, E.J., "Processing of Discontinuously-Reinforced Metal Matrix Composites," by Rapid Solidification, Progress in Material Science, 39: 317-409. 1995.

[16] M.K. Surappa. J. Mater., "Fabrication of Al-Al2O3/Grp Metal Matrix Composites 3079 ," in Proc. Tech. 63, 325-333.1997.

[17] D.M. Skibo, D.M. Schuster, L. Jolla, "Process for preparation of composite materials Containing nonmetallic particles in a metallic matrix, and composite materials made by," US Patent No. 4786 467, 1988. 